\title{
Prevalence and risk factors of low back and pelvic pain in women with rectus abdominis diastasis: a multicenter retrospective cohort study
}

\author{
Sue Yuan ${ }^{1,2}$, Honghong Wang ${ }^{2}$, and Jie Zhou ${ }^{3}$ \\ 'Teaching and Research Section of Clinical Nursing, Xiangya Hospital of Central South University, Changsha, Hunan, China \\ ${ }^{2}$ Xiangya Nursing School, Central South University, Changsha, Hunan, China \\ ${ }^{3}$ Department of Anesthesiology, Perioperative and Pain Medicine, Brigham and Women's Hospital, Harvard Medical School, Boston, MA, USA
}

Received August 13, 2021

Revised September 11, 2021

Accepted September 23, 2021

Handling Editor: Jeong-Gill Leem

\section{Correspondence}

Jie Zhou

Department of Anesthesiology, Perioperative and Pain Medicine, Brigham and Women's Hospital, Harvard Medical School, 75 Francis Street, Boston, MA 02115, USA

Tel: +1-617-732-8220

Fax: +1-617-264-6841

E-mail: jzhou5@BWH.HARVARD.EDU
Background: To explore the association between low back pain (LBP) and pelvic pain (PP) and rectus abdominis diastasis (RAD) in postpartum women and identify the characteristics and risk factors.

Methods: Women diagnosed with RAD and a history of labor and delivery, between 2009 and 2018, were identified from six hospitals within the Partners Healthcare System. Univariate and multivariable binary logistic regression analyses were used to identify the risk factors associated with pain.

Results: Age at onset of RAD in the non-cesarean delivery group was earlier than those in cesarean delivery $(C D)$ group $(P=0.017)$. Women who underwent $C D$ demonstrated 4.5 times greater risk of RAD than those who had no CD exposure. The cumulative composition ratio of LBP at every age stage of the period from 8 years pre-first delivery to 8 years post-first delivery was significantly higher than the other five conditions (RAD, umbilical hernia, PP, depressive disorder [DD], and strain of muscle, fascia, and tendon [SMFT]) ( $P$ for trend $<0.001)$. Women with DD, SMFT, and PP were more likely to have LBP (odds ratio $[\mathrm{OR}]=1.91,95 \%$ confidence interval $[\mathrm{Cl}] 1.06$ to $3.47, P=0.032 ; \mathrm{OR}=4.50,95 \% \mathrm{Cl} 1.64$ to $12.36, P=0.003$; OR = $2.14,95 \% \mathrm{Cl} 1.17$ to $3.89, P=0.013$; respectively).

Conclusions: In postpartum women with RAD, DD, SMFT, and PP were found to be risk factors contributing to the development of LBP. Race and LBP also played roles in the development of PP.

Key Words: Cesarean Section; Chronic Pain; Delivery, Obstetric; Depressive Disorder; Diastasis, Muscle; Low Back Pain; Pelvic Pain; Postpartum Period; Pregnancy; Race Factors; Rectus Abdominis; Risk Factors.

\section{INTRODUCTION}

Rectus abdominis diastasis (RAD) is defined as a condition in which the rectus muscles are separated more than 2 $\mathrm{cm}$. The prevalence in pregnancy and postpartum women could range from $30 \%$ to $46.5 \%$ [1-4]. Number of pregnan- cies, multiple gestations, and open abdominal surgical procedures are potential risk factors in the development of RAD [3]. A previous study by the authors demonstrated that the risk of RAD in women is 1.9 times greater than that in men, and the age at onset of RAD in women is also much earlier than that of men [5]. In addition, chronic (c) This is an open-access article distributed under the terms of the Creative Commons Attribution Non-Commercial License (http://creativecommons.org/licenses/by-nc/4.0/), which permits unrestricted non-commercial use, distribution, and reproduction in any medium, provided the original work is properly cited.

(C) The Korean Pain Society, 2022
Author contributions: Sue Yuan: Writing/manuscript preparation; Honghong Wang: Supervision; Jie Zhou: Supervision. 
pain may develop in RAD patients, and the previous study confirmed that chronic pain was an important concomitant condition in the RAD population [5]. But few studies have focused on the relationship between RAD and low back pain (LBP)/pelvic pain (PP).

We conducted this multicenter retrospective cohort study in postpartum women with diagnosis of RAD to explore the association between LBP/PP and RAD in women with a history of vaginal delivery (VD) compared to those with one or more instances of cesarean delivery (CD) exposures.

\section{MATERIALS AND METHODS}

This retrospective study analyzed characteristics of women with a history of labor and delivery who were diagnosed with RAD from six hospitals within the Partners Healthcare System in Massachusetts, USA. The review board of the Research Patient Data Registry approved the study protocol (\#2018P003056).

Medical records of women with a diagnosis of RAD, defined by the International Classification of Diseases codes (Ninth Revision Clinical Modification ICD-9-CM and Tenth Revision ICD-10-CM), from January 1, 2009 to December 31, 2018 from six hospitals of the Partners Healthcare System were collected. Women who delivered at these hospitals with delivery notes available were included. Data including demographic information, diagnosis (Table 1), health history, delivery notes, and ultrasound (when available) were extracted.

The demographic and health history variables included in this study were age at onset of RAD, age of labor and delivery, body mass index (BMI), race or ethnicity, smoking state, and alcohol use. Only records from first labor and delivery were analyzed. Apart from LBP and PP, other concomitant conditions that were identified included hernia, mixed incontinence, depressive disorder (DD), and strain of muscle, fascia, and tendon (SMFT) (See Table 1 for ICD codes used in database search). In this study, there was a focus on the trends of cumulative composition ratio for conditions, including RAD, umbilical hernia, LBP, PP, DD, and SMFT and the timing relationship between them and the first delivery. The timing relationship between LBP/PP and RAD were also analyzed. The cumulative composition ratio of disease was defined as the percentage of patients who were diagnosed with the disease in the past or current year, accounting for all patients. The time interval was set as 2-years, centered on labor and delivery.

SPSS Statistics version 20 (IBM Corp., Armonk, NY) was used to perform all statistical analyses. Data was summarized as frequencies and percentages or mean and stan-

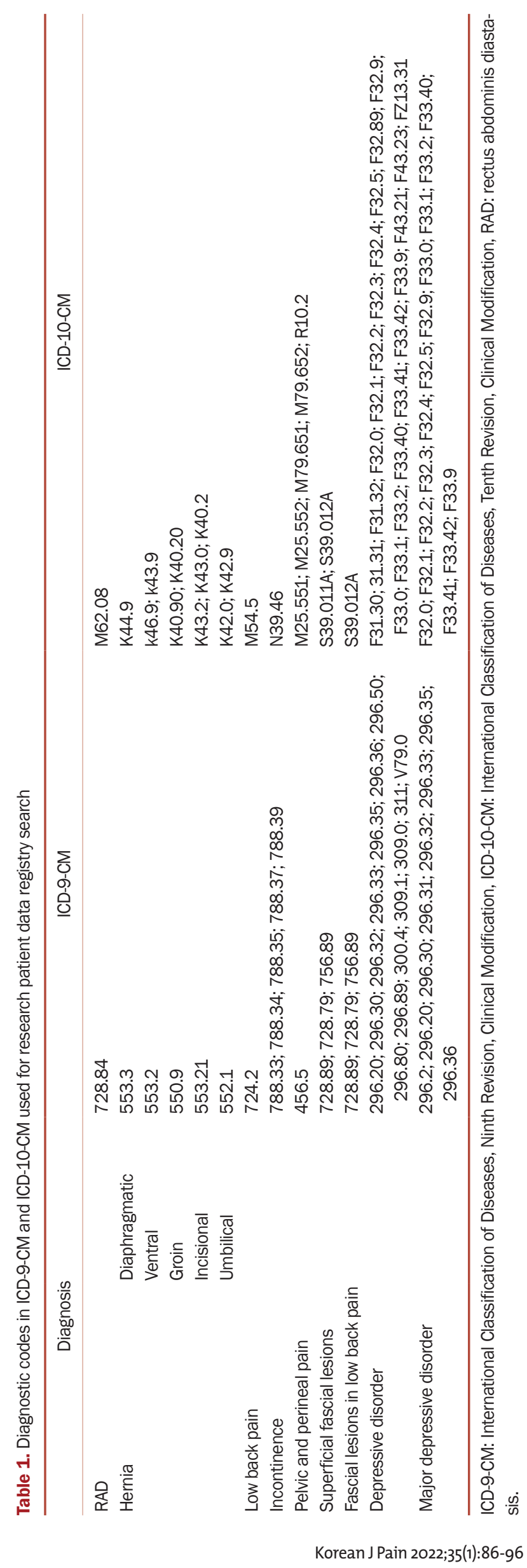


dard deviation. Pearson's and continuity correction chisquare tests and Fisher's exact test were used for counting data. The Mann-Whitney U nonparametric test was used for continuous variables. Linear-by-Linear association chi-square tests were used to test the difference between the cumulative composition ratio of conditions. Wilcoxon's W nonparametric test was used to test the difference of age at onset between groups. Univariate and multivariate binary logistic regression analysis models were used to identify the independent risk factors, using LBP and PP as the dependent variables, respectively. All variables on univariate analysis were used to identify the independent risk factors of LBP and PP as well. The odds ratio (OR) and 95\% confidence interval (CI) were estimated from multivariate regression analysis. A forward stepwise regression analysis $(\alpha$ entry $=0.10, \alpha$ removal $=0.10$ ) was used to reduce confounding bias. A two-tailed $P$ value less than 0.05 was considered statistically significant for all tests. The risk ratio formula was used to calculate the relative risk.

\section{RESULTS}

Of the 866 women with RAD, 417 women underwent labor delivery. Data from the $317(76.0 \%)$ women who had complete delivery operative notes were analyzed. Of the 317 women, $218(68.8 \%)$ had one or more CD history. Age at onset of RAD in the non-CD group (without CD exposure) was earlier than those in CD group $(P=0.017)$ (Fig. 1). Women who underwent $C D$ demonstrated 4.5 times greater risk of RAD than those who had no CD exposure. Most CDs were performed with Pfannenstiel skin-incision (98.2\%), low transverse uterine incision (93.1\%), and suture closure method (80.7\%). Epidural anesthesia accounted for $73.7 \%$ of all anesthesia in non-CD group, whereas spinal anesthesia accounted for $57.3 \%$ in CD group (Table 2).

The age of first delivery, onset age of RAD, and BMI in CD group was significantly higher than that in non-CD group (35.5 years old vs. 33.2 years old, $P<0.001 ; 37.5$ years old vs. 35.9 years old, $P=0.004 ; 28.3 \mathrm{~kg} / \mathrm{m}^{2}$ vs. $26.0 \mathrm{~kg} / \mathrm{m}^{2}$, $P=0.001$; respectively). The distribution of the onset age of RAD in the CD group was significantly different from that in non-CD group as well ( $P$ for trend $=0.017$ ) (Fig. 1). One hundred thirty-two cases $(41.6 \%)$ in this population were alcohol users. Adhesions in the abdominal and/or pelvic cavity were noted in 40 subjects $(17.3 \%)$ who underwent CD procedures (Table 2). In this population, the rates of concomitant LBP, DD, umbilical hernia, PP, and SMFT were $24.6 \%, 23.0 \%, 22.7 \%, 21.8 \%$, and $6.0 \%$, respectively (Table 2). The prevalence of LBP, PP, mixed incontinence, hernias, DD, and SMFT in the non-CD group did not differ from that in the CD group $(20.2 \%$ vs. $26.6 \%, P=0.220$; $21.2 \%$ vs. $22.0 \%, P=0.872 ; 5.1 \%$ vs. $3.7 \%, P=0.566 ; 31.2 \%$ vs. $31.2 \%, P=0.983 ; 20.2 \%$ vs. $24.3 \%, P=0.421 ; 2.0 \%$ vs. $7.8 \%, P$ $=0.080$; respectively) (Table 2).

The cumulative composition ratio of LBP in every age stage of the period from 8 years pre-first delivery to 8 years post-first delivery was significantly higher than in the other five conditions (RAD, umbilical hernia, PP, DD, and SMFT) ( $P$ for trend $<0.001$ ) (Fig. 2). Before the first delivery, the proportion of the patients with LBP was $57.7 \%$ (45/78), which was higher than other concomitant condition $(P<$ 0.001 ), and the rate increased rapidly up to $83.3 \%$ within 2 years after first delivery $(P=0.001)$ (Fig. 3). In addition, after first delivery, 43 of 69 subjects (62.3\%) had PP compared to 20 of 69 (29.0\%) before first delivery $(P<0.001)$ (Fig. 2).

Before RAD, 13 of 20 cases $(65.0 \%)$ had LBP in the nonCD group compared with 42 of $58(72.4 \%)$ in CD group ( $P$ $=0.531$ ). There were no significant differences in the distribution of the age at onset of LBP between the CD group and non-CD groups ( $P$ for trend $=0.235$ ). The rate of $P P$ the in non-CD group was $52.4 \%$ compared to $56.3 \%$ in the CD group before RAD ( $P=0.766)$. In the case of PP, 20 of 48 women $(41.7 \%)$ first encountered pain within 2 years before having RAD in the CD group compared to 10 of 21 (47.6\%) in the non-CD group $(P=0.646)$. The distribution of

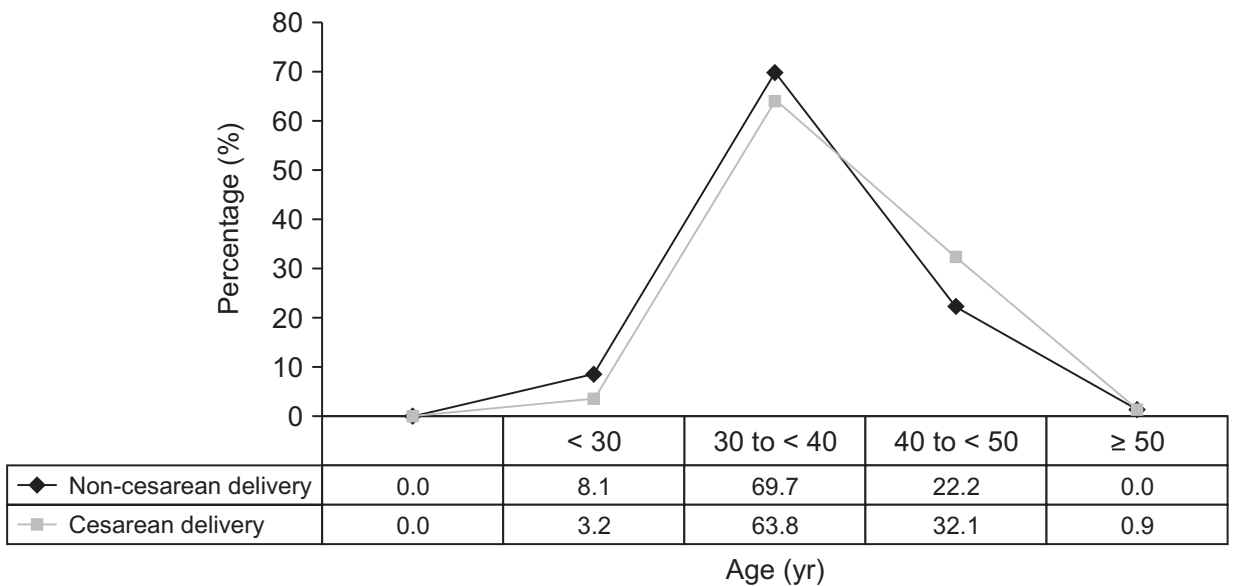

Fig. 1. The comparison of onset age of rectus abdominis diastasis between noncesarean delivery and cesarean delivery group. 
Table 2. Patients demographics and characteristics

\begin{tabular}{|c|c|c|c|c|}
\hline Characteristics & Non-CD group $(\mathrm{n}=99)$ & CD group $(n=218)$ & Total $(n=317)$ & $P$ value \\
\hline \multicolumn{5}{|l|}{ Demographic characteristic } \\
\hline Age of first delivery (yr) & $33.2 \pm 4.3$ & $35.5 \pm 4.4$ & $34.8 \pm 4.5$ & $<0.001^{a}$ \\
\hline Age at onset of RAD (yr) & $35.9 \pm 4.7$ & $37.5 \pm 4.6$ & $37.0 \pm 4.7$ & $0.004^{a}$ \\
\hline \multicolumn{5}{|l|}{ Race or ethnic group } \\
\hline Black/African & $3(3.0)$ & $12(5.5)$ & $15(4.7)$ & 0.868 \\
\hline Asian & $7(7.1)$ & $12(5.5)$ & $19(6.0)$ & \\
\hline Hispanic & $4(4.0)$ & $10(4.6)$ & $14(4.4)$ & \\
\hline White & $80(80.8)$ & $172(78.9)$ & $252(79.5)$ & \\
\hline Others & $5(5.1)$ & $12(5.5)$ & $17(5.4)$ & \\
\hline \multicolumn{5}{|l|}{ Body mass index $\left(\mathrm{kg} / \mathrm{m}^{2}\right)$} \\
\hline Mean & $26.0 \pm 4.6$ & $28.3 \pm 5.9$ & $27.6 \pm 5.6$ & $0.001^{a}$ \\
\hline 18.0 to $<25$ & $45(45.5)$ & $68(31.2)$ & $112(35.3)$ & $0.028^{b}$ \\
\hline 25 to $<30$ & $35(35.4)$ & $83(38.1)$ & $118(37.2)$ & \\
\hline 30 to $<40$ & $18(18.2)$ & $58(26.6)$ & $76(24.0)$ & \\
\hline$\geq 40$ & $1(1.0)$ & $10(4.6)$ & $11(3.5)$ & \\
\hline \multicolumn{5}{|l|}{ Social history } \\
\hline Smoking state & $9(9.1)$ & $28(12.8)$ & 37 (11.7) & 0.335 \\
\hline Alcohol use & $48(48.5)$ & $84(38.5)$ & $132(41.6)$ & 0.096 \\
\hline Depressive disorder & $20(20.2)$ & $53(24.3)$ & $73(23.0)$ & 0.421 \\
\hline \multicolumn{5}{|l|}{ Concomitant conditions } \\
\hline Pelvic pain & $21(21.2)$ & $48(22.0)$ & $69(21.8)$ & 0.872 \\
\hline Low back pain & $20(20.2)$ & $58(26.6)$ & $78(24.6)$ & 0.220 \\
\hline Strain of muscle, fascial and tendon & $2(2.0)$ & $17(7.8)$ & $19(6.0)$ & $0.080^{c}$ \\
\hline Mixed incontinence & $5(5.1)$ & $8(3.7)$ & $13(4.1)$ & 0.566 \\
\hline Hernias & $31(31.3)$ & $68(31.2)$ & $99(31.2)$ & 0.983 \\
\hline Diaphragmatic hernia & $1(1.0)$ & $5(2.3)$ & $6(1.9)$ & $0.740^{c}$ \\
\hline Ventral hernia & $13(13.1)$ & $38(17.4)$ & $51(16.1)$ & 0.334 \\
\hline Groin hernia & $5(5.1)$ & $3(1.4)$ & $8(2.5)$ & $0.122^{c}$ \\
\hline Incisional hernia & 0 & $8(3.7)$ & $8(2.5)$ & $0.061^{d}$ \\
\hline Umbilical hernia & $26(26.3)$ & $46(21.1)$ & $72(22.7)$ & 0.309 \\
\hline \multicolumn{5}{|c|}{ Adhesions in abdominal and/or pelvic cavity } \\
\hline Minimal & - & $8(3.7)$ & - & - \\
\hline Moderate & - & $16(7.3)$ & - & - \\
\hline Dense & - & $16(7.3)$ & - & - \\
\hline Not reported & $99(100.0)$ & $178(81.7)$ & - & - \\
\hline \multicolumn{5}{|l|}{ Characteristics of first delivery procedure } \\
\hline \multicolumn{5}{|l|}{ Skin-incision type } \\
\hline Pfannenstiel & - & $214(98.2)$ & - & - \\
\hline Vertical & - & $4(1.8)$ & - & - \\
\hline \multicolumn{5}{|l|}{ Closure method } \\
\hline Staples & - & $42(19.3)$ & - & - \\
\hline Suture & - & $176(80.7)$ & - & - \\
\hline \multicolumn{5}{|l|}{ Uterine incision } \\
\hline Low transverse & - & $203(93.1)$ & - & - \\
\hline Other & - & $15(6.9)$ & - & - \\
\hline \multicolumn{5}{|l|}{ Anesthesia type } \\
\hline Spinal & $2(2.0)$ & $125(57.3)$ & $127(40.1)$ & - \\
\hline Epidural & $73(73.7)$ & $62(28.5)$ & $135(42.6)$ & - \\
\hline Combined spinal epidural & - & $21(9.6)$ & $21(6.6)$ & - \\
\hline General & - & $10(4.6)$ & $10(3.2)$ & - \\
\hline Local & $9(9.1)$ & - & $9(2.8)$ & - \\
\hline None & $15(15.2)$ & - & $15(4.7)$ & - \\
\hline
\end{tabular}

Values are presented as mean \pm standard deviation or number (\%).

$\mathrm{CD}$ : cesarean delivery, RAD: rectus abdominis diastasis.

${ }^{a}$ Mann-Whitney U nonparametric test. ${ }^{b}$ Likelihood ratio chi-square test. ${ }^{\circ}$ Continuity correction chi-square test. ${ }^{d}$ Fisher's exact test. 


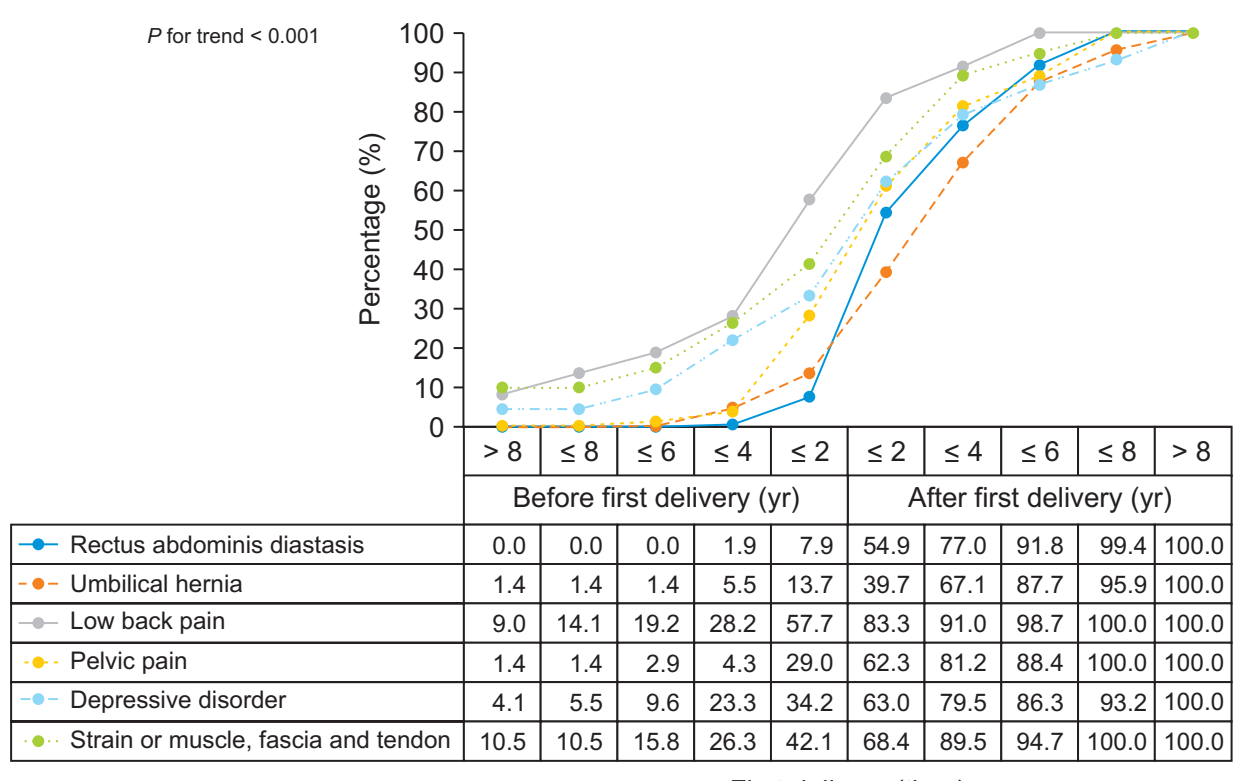

First delivery (time)

A

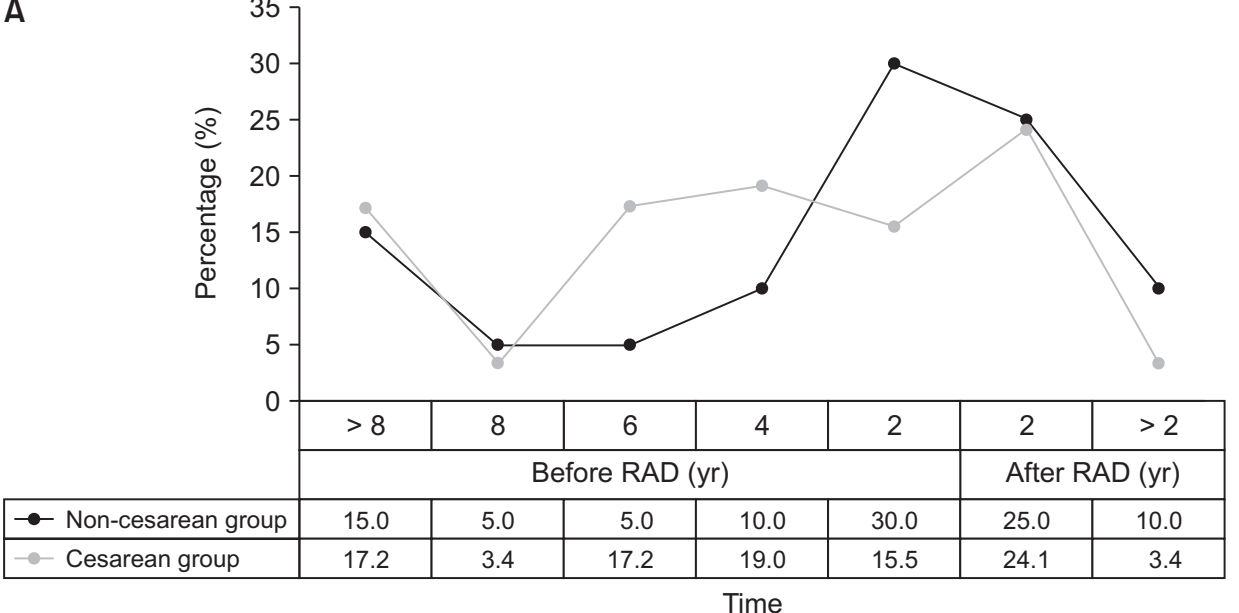

B

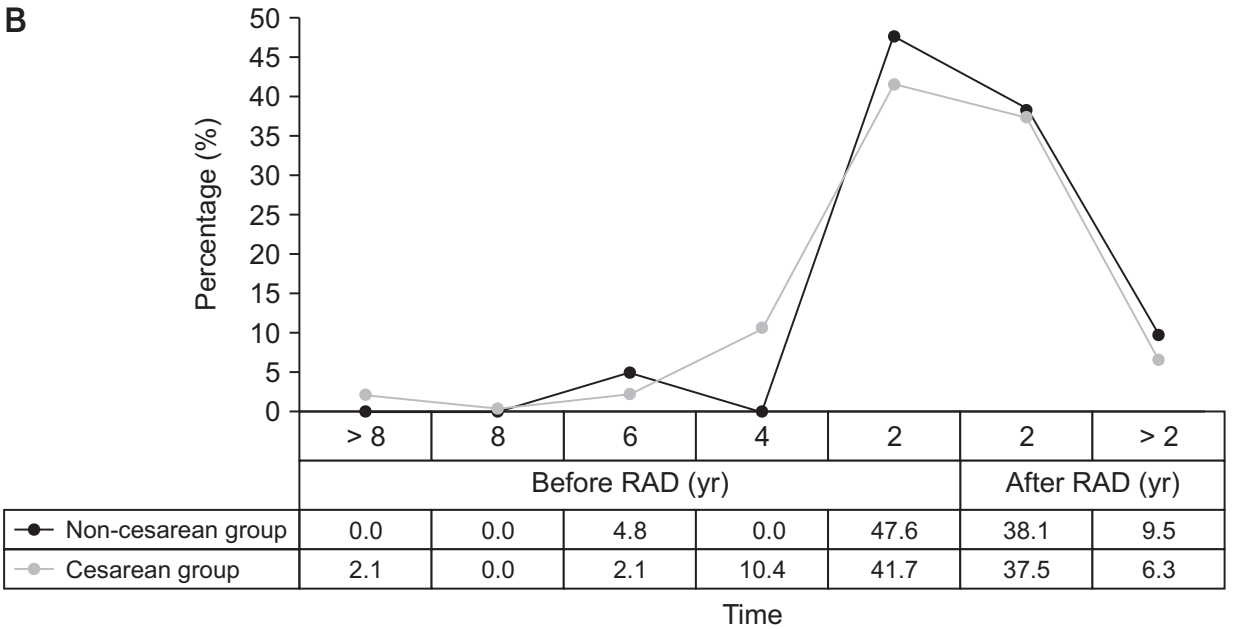

Fig. 2. The time relations between concomitant conditions and first delivery.
Fig. 3. The relation between low back pain (LBP)/pelvic pain (PP) and rectus abdominis diastasis (RAD). (A) Onset age of $L B P$ related to RAD. (B) Onset age of PP related to RAD. age at onset of $\mathrm{PP}$ in the CD group also did not differ from that in non-CD group ( $P$ for trend $=0.496$ ).

For the women with RAD in this study, subjects with LBP had higher prevalence of DD (34.6\% vs. 19.3\%, $P=0.005)$, SMFT (15.4\% vs. $2.9 \%, P<0.001)$, and PP (34.6\% vs. $17.6 \%, P$ $=0.002)$ than those without LBP (Table 3). Univariate and 
Table 3. Characteristics of postpartum rectus abdominis diastasis patients with and without low back pain

\begin{tabular}{|c|c|c|c|}
\hline Variable & Without low back pain $(n=239)$ & With low back pain $(n=78)$ & $P$ value \\
\hline \multicolumn{4}{|l|}{ Demographic characteristics } \\
\hline \multicolumn{4}{|l|}{ Age (yr) } \\
\hline$<30$ & $6(2.5)$ & $1(1.3)$ & $0.303^{a}$ \\
\hline 30 to $<40$ & $145(60.7)$ & $41(52.6)$ & \\
\hline 40 to $<50$ & $86(36.0)$ & $36(46.2)$ & \\
\hline 50 to $<60$ & $2(0.8)$ & 0 & \\
\hline \multicolumn{4}{|l|}{ Race or ethnic group } \\
\hline Black/African & $10(4.2)$ & $5(6.4)$ & $0.788^{a}$ \\
\hline Asian & $13(5.4)$ & $6(7.7)$ & \\
\hline Hispanic & $10(4.2)$ & $4(5.1)$ & \\
\hline White & $194(81.2)$ & $58(74.4)$ & \\
\hline Others & $12(5.0)$ & $5(6.4)$ & \\
\hline \multicolumn{4}{|l|}{ Body mass index $\left(\mathrm{kg} / \mathrm{m}^{2}\right)$} \\
\hline 18.5 to $<25$ & $90(37.7)$ & $22(28.2)$ & $0.419^{a}$ \\
\hline 25 to $<30$ & $86(36.0)$ & $32(41.0)$ & \\
\hline 30 to $<40$ & $56(23.4)$ & $20(25.6)$ & \\
\hline$\geq 40$ & $7(2.9)$ & $4(5.1)$ & \\
\hline \multicolumn{4}{|l|}{ Delivery mode } \\
\hline Non-cesarean & 79 (33.1) & $20(25.6)$ & 0.220 \\
\hline Cesarean & $160(66.9)$ & $58(74.4)$ & \\
\hline \multicolumn{4}{|l|}{ Social history } \\
\hline Smoking state & 27 (11.3) & $10(12.8)$ & 0.716 \\
\hline Alcohol use & $103(43.1)$ & $29(37.2)$ & 0.357 \\
\hline Depressive disorder & 46 (19.2) & 27 (34.6) & 0.005 \\
\hline \multicolumn{4}{|l|}{ Concomitant conditions } \\
\hline Pelvic pain & $42(17.6)$ & $27(34.6)$ & 0.002 \\
\hline Strain of muscle, fascial and tendon & $7(2.9)$ & $12(15.4)$ & $<0.001$ \\
\hline Adhesions & $30(12.6)$ & $10(12.8)$ & 0.951 \\
\hline Hernia status & $77(32.2)$ & $22(28.2)$ & 0.507 \\
\hline \multicolumn{4}{|l|}{ Hernia type } \\
\hline Diaphragmatic hernia & $2(0.8)$ & $4(5.1)$ & $0.053^{b}$ \\
\hline Ventral hernia & $38(15.9)$ & $13(16.7)$ & 0.873 \\
\hline Groin hernia & $4(1.7)$ & $4(5.1)$ & $0.203^{b}$ \\
\hline Incisional hernia & $7(2.9)$ & $1(1.3)$ & $0.697^{\mathrm{b}}$ \\
\hline Umbilical hernia & $57(23.8)$ & $15(19.2)$ & 0.398 \\
\hline
\end{tabular}

Values are presented as number (\%).

aikelihood ratio chi-square test. ${ }^{\mathrm{b}}$ Continuity correction chi-square test.

multivariate regression analysis identified that women with DD, SMFT, and PP were more likely to have LBP (OR $=1.91,95 \% \mathrm{CI} 1.06$ to $3.47, P=0.032 ; \mathrm{OR}=4.50,95 \% \mathrm{CI} 1.64$ to $12.36, P=0.003$; $\mathrm{OR}=2.14,95 \% \mathrm{CI} 1.17$ to $3.89, P=0.013$; respectively) (Table 4).

Women with PP in the present study had higher coexisting conditions of LBP $(39.1 \%$ vs. $20.6 \%, P<0.001)$ and SMFT (13.0\% vs. $4.0 \%, P=0.005)$ as well. Interestingly, the occurrence of umbilical hernia in the PP group was significantly lower than non-PP group ( $10.1 \%$ vs. $26.2 \%, P=0.005$ ) (Table 5). Univariate and multivariate regression analysis also identified that women with LBP tended to have PP (OR = $2.44,95 \%$ CI 1.36 to $4.40, P=0.003)$. Notably, these analyses implied that women with concomitant umbilical hernia were less likely to have PP (OR $=0.33,95 \%$ CI 0.14 to $0.78, P$
$=0.011$ ). Additionally, subjects of Hispanic ethnicity in this sample had a higher risk of concomitant $\mathrm{PP}$ than others (OR $=3.75,95 \%$ CI 1.21 to $11.63, P=0.022$ ) (Table 6).

\section{DISCUSSION}

The principal findings of this retrospective cohort investigation of a multi-institutional sample of postpartum women with concomitant RAD are as follows. First, women who had a history of $\mathrm{CD}$ procedure exposure demonstrated 4.5 times greater risk of RAD than those women who delivered vaginally. Second, the onset age range of RAD in both the $\mathrm{CD}$ and non-CD group were concentrated between those 30 to 40 years old, even though the onset age in the non- 
Table 4. Univariate and multivariate binary regression analyses of underlying factors to low back pain in postpartum patients with rectus abdominis diastasis

\begin{tabular}{|c|c|c|c|c|}
\hline \multirow{2}{*}{ Variable } & \multicolumn{2}{|c|}{ Univariate } & \multicolumn{2}{|c|}{ Multivariate } \\
\hline & $P$ value & OR (95\% Cl) & $P$ value & OR $(95 \% \mathrm{Cl})$ \\
\hline \multicolumn{5}{|l|}{ Demographic characteristics } \\
\hline \multicolumn{5}{|l|}{ Age $(y r)$} \\
\hline$<30$ & & 1 & 0.405 & NS \\
\hline 30 to $<40$ & 0.629 & $1.70(0.20-14.50)$ & & \\
\hline 40 to $<50$ & 0.402 & $2.51(0.29-21.62)$ & & \\
\hline 50 to $<60$ & 0.999 & 0 & & \\
\hline \multicolumn{5}{|l|}{ Race or ethnic group } \\
\hline Black/African & & 1 & 0.529 & NS \\
\hline Asian & 0.914 & $0.92(0.22-3.92)$ & 0.346 & NS \\
\hline Hispanic & 0.782 & $0.80(0.17-3.89)$ & 0.339 & NS \\
\hline White & 0.365 & $0.60(0.20-1.82)$ & 0.602 & NS \\
\hline Others & 0.811 & $0.83(0.19-3.72)$ & 0.808 & NS \\
\hline \multicolumn{5}{|l|}{ Body mass index $\left(\mathrm{kg} / \mathrm{m}^{2}\right)$} \\
\hline 18.5 to $<25$ & & 1 & 0.622 & NS \\
\hline 25 to $<30$ & 0.183 & $1.52(0.82-2.82)$ & & \\
\hline 30 to $<40$ & 0.282 & $1.49(0.73-2.92)$ & & \\
\hline$\geq 40$ & 0.205 & $2.34(0.63-8.70)$ & & \\
\hline Cesarean exposure & 0.221 & $1.43(0.81-2.55)$ & 0.628 & NS \\
\hline \multicolumn{5}{|l|}{ Social history } \\
\hline Smoking state & 0.716 & $1.16(0.53-2.51)$ & 0.568 & NS \\
\hline Alcohol use & 0.358 & $0.78(0.46-1.32)$ & 0.327 & NS \\
\hline Depressive disorder & 0.006 & $2.22(1.23-3.19)$ & 0.032 & $1.91(1.06-3.47)$ \\
\hline \multicolumn{5}{|l|}{ Concomitant conditions } \\
\hline Strain of muscle, fascial and tendon & $<0.001$ & $6.03(2.28-15.92)$ & 0.003 & $4.50(1.64-12.36)$ \\
\hline Adhesions & 0.951 & $1.03(0.48-2.20)$ & N/A & N/A \\
\hline Pelvic pain & 0.002 & $2.48(1.40-4.41)$ & 0.013 & $2.14(1.17-3.89)$ \\
\hline Hernia status & 0.507 & $0.83(0.47-1.45)$ & 0.575 & NS \\
\hline \multicolumn{5}{|l|}{ Hernia type } \\
\hline Diaphragmatic hernia & 0.034 & $6.41(0.15-35.68)$ & 0.326 & NS \\
\hline Ventral hernia & 0.873 & $1.06(0.53-2.11)$ & 0.724 & NS \\
\hline Groin hernia & 0.108 & $3.18(0.78-13.01)$ & 0.065 & NS \\
\hline Incisional hernia & 0.427 & $0.43(0.05-3.51)$ & 0.182 & NS \\
\hline Umbilical hernia & 0.399 & $0.76(0.40-1.44)$ & 0.667 & NS \\
\hline
\end{tabular}

Race categorized as categorical covariates with other variables were subjected to multivariate regression model using forward stepwise variable selection.

OR: odds ratio, Cl: confidence interval, N/A: not applicable, NS: not significant.

CD group was significantly earlier than those who underwent CD. Third, the prevalence of LBP and PP among this population was high. Forth, the prevalence and characteristics of the pain in women with a history of non-CD did not differentiate from those with $\mathrm{CD}$. Fifth, the age at onset of LBP/PP showed no difference between the $\mathrm{CD}$ and nonCD groups in women with RAD. Sixth, women with DD in the RAD population had approximately 2 times greater risk of LBP than those without it. Seventh, PP and SMFT are risk factors of the development of LBP in women with RAD. Eighth, LBP was found to be significantly associated with PP in women with RAD. Finally, Hispanic race was demonstrated to be a role in the development of PP in women with RAD.

LBP and PP were thought to be related to first labor and delivery in women with RAD. LBP and PP were thought to be related to pregnancy [6]. Moreover, a 2012 review reported that the global prevalence of LBP among women was $8.7 \%$, and several studies reported that the prevalence of LBP in women with RAD ranged from $24 \%$ to $69 \%$, which is much higher than the global prevalence $[4,7-9]$. The present study confirmed that LBP/PP was associated with labor and delivery in RAD patients, no matter if it was via VD or CD. In this study, over one quarter of LBP patients had the first onset during the period between 2 years preand post-first delivery, while one-third of the new onsets 
Table 5. Characteristics of postpartum rectus abdominis diastasis patients with and without pelvic pain

\begin{tabular}{|c|c|c|c|}
\hline Variable & Without pelvic pain $(n=248)$ & With pelvic pain $(n=69)$ & $P$ value \\
\hline \multicolumn{4}{|l|}{ Demographic characteristics } \\
\hline \multicolumn{4}{|l|}{ Age (yr) } \\
\hline$<30$ & $3(1.2)$ & $4(5.8)$ & $0.034^{\mathrm{a}}$ \\
\hline 30 to $<40$ & $154(62.1)$ & $32(46.4)$ & \\
\hline 40 to $<50$ & $90(36.3)$ & $32(46.4)$ & \\
\hline 50 to $<60$ & $1(0.4)$ & $1(1.4)$ & \\
\hline \multicolumn{4}{|l|}{ Race or ethnic group } \\
\hline Black/African & $10(4.0)$ & $5(7.2)$ & 0.036 \\
\hline Asian & $17(6.9)$ & $2(2.9)$ & \\
\hline Hispanic & $7(2.8)$ & 7 (10.1) & \\
\hline White & $202(81.5)$ & $50(72.5)$ & \\
\hline Others & $12(4.8)$ & $5(7.2)$ & \\
\hline \multicolumn{4}{|l|}{ Body mass index $\left(\mathrm{kg} / \mathrm{m}^{2}\right)$} \\
\hline 18.5 to $<25$ & $90(36.3)$ & $22(31.9)$ & $0.673^{\mathrm{a}}$ \\
\hline 25 to $<30$ & $92(37.1)$ & $26(37.7)$ & \\
\hline 30 to $<40$ & $59(23.8)$ & $17(24.6)$ & \\
\hline$\geq 40$ & $7(2.8)$ & $4(5.8)$ & \\
\hline \multicolumn{4}{|l|}{ Delivery mode } \\
\hline Non-cesarean & $78(31.5)$ & $21(30.4)$ & 0.872 \\
\hline Cesarean & $170(68.5)$ & $48(69.6)$ & \\
\hline \multicolumn{4}{|l|}{ Social history } \\
\hline Smoking state & $30(12.1)$ & 7 (10.1) & 0.655 \\
\hline Alcohol abuse & $102(41.1)$ & $30(43.5)$ & 0.726 \\
\hline Depressive disorder & $53(21.4)$ & $20(29.0)$ & 0.184 \\
\hline \multicolumn{4}{|l|}{ Accompanying systems } \\
\hline Strain of muscle, fascial and tendon & $10(4.0)$ & $9(13.0)$ & 0.005 \\
\hline Adhesions & $30(12.1)$ & $10(14.5)$ & 0.596 \\
\hline Low back pain & $51(20.6)$ & 27 (39.1) & $<0.001$ \\
\hline Hernia status & $84(33.9)$ & $15(21.7)$ & 0.054 \\
\hline \multicolumn{4}{|l|}{ Hernia type } \\
\hline Diaphragmatic hernia & $3(1.2)$ & $3(4.3)$ & $0.233^{b}$ \\
\hline Ventral hernia & $44(17.7)$ & $7(10.1)$ & 0.129 \\
\hline Groin hernia & $5(2.0)$ & $3(4.3)$ & $0.510^{b}$ \\
\hline Incisional hernia & $7(2.8)$ & $1(1.4)$ & $0.834^{b}$ \\
\hline Umbilical hernia & $65(26.2)$ & $7(10.1)$ & 0.005 \\
\hline
\end{tabular}

Values are presented as number (\%).

${ }^{a}$ Likelihood ratio chi-square test. ${ }^{b}$ Continuity correction chi-square test.

of PP arose during this period. The prevalence of LBP/PP in this study was less than thirty percent, which is lower than reported in previous studies (approximately half in the general pregnancy population) $[6,10,11]$. This could be due to a different study method, as only individuals with diagnosed ICD codes were included.

The authors identified the following innovative findings. Firstly, the data demonstrated that the age at onset of $\mathrm{LBP} / \mathrm{PP}$ showed no difference between the $\mathrm{CD}$ and non-CD groups in women with RAD. Secondly, it was found that the risk of RAD in women who underwent $\mathrm{CD}$ delivery was 4.5 times that of those who delivered vaginally. Thirdly, the age at onset of RAD in women who had undergone VD was significantly younger than those who underwent $C D$. Interestingly, the onset age range of both groups was con- centrated between 30 and 40 years old, which confirmed that pregnancy and CD were important risk factors contributing to RAD [12-14]. The results of the present study also implied that the importance of $\mathrm{CD}$ in the development of RAD might be underestimated.

LBP interacted with DD in postpartum women with concomitant RAD. Several investigations have linked DD to chronic spinal pain $[15,16]$. Oon-Arom et al. [16] found that patients with physical pain symptoms tended to express some subjective symptoms of DD. Schmaling and Nounou [15] reported DD patients were more likely to develop chronic spinal pain than those participants without DD.

The present study also confirmed that women with DD in the RAD population had approximately a 2 times greater risk of LBP than those without it. The data demonstrated 
Table 6. Univariate and multivariate binary regression analyses of underlying factors to pelvic pain in postpartum patients with rectus abdominis diastasis

\begin{tabular}{|c|c|c|c|c|}
\hline \multirow{2}{*}{ Variable } & \multicolumn{2}{|c|}{ Univariate } & \multicolumn{2}{|c|}{ Multivariate } \\
\hline & $P$ value & OR $(95 \% \mathrm{Cl})$ & $P$ value & OR $(95 \% \mathrm{Cl})$ \\
\hline \multicolumn{5}{|l|}{ Demographic characteristics } \\
\hline \multicolumn{5}{|l|}{ Age $(y r)$} \\
\hline$<30$ & & 1.00 & 0.304 & NS \\
\hline 30 to $<40$ & 0.018 & $0.16(0.03-0.73)$ & & \\
\hline 40 to $<50$ & 0.095 & $0.27(0.06-1.26)$ & & \\
\hline 50 to $<60$ & 0.858 & $0.75(0.03-17.51)$ & & \\
\hline \multicolumn{5}{|l|}{ Race or ethnic group } \\
\hline Black/African & & 1.00 & 0.126 & NS \\
\hline Asian & 0.118 & $0.24(0.04-1.45)$ & 0.200 & NS \\
\hline Hispanic & 0.365 & $2.00(0.45-8.96)$ & 0.022 & $3.75(1.21-11.63)$ \\
\hline White & 0.217 & $0.50(0.16-1.51)$ & 0.468 & NS \\
\hline Others & 0.811 & $0.83(0.19-3.72)$ & 0.237 & NS \\
\hline \multicolumn{5}{|l|}{ Body mass index $\left(\mathrm{kg} / \mathrm{m}^{2}\right)$} \\
\hline 18.5 to $<25$ & & 1.00 & 0.699 & NS \\
\hline 25 to $<30$ & 0.656 & $1.16(0.61-2.19)$ & & \\
\hline 30 to $<40$ & 0.651 & $1.18(0.58-2.41)$ & & \\
\hline$\geq 40$ & 0.205 & $2.34(0.63-8.70)$ & & \\
\hline Cesarean exposure & 0.872 & $1.05(0.59-1.87)$ & 0.765 & NS \\
\hline \multicolumn{5}{|l|}{ Social history } \\
\hline Smoking state & 0.656 & $0.82(0.34-1.96)$ & 0.575 & NS \\
\hline Alcohol abuse & 0.726 & $1.10(0.64-1.89)$ & 0.680 & NS \\
\hline Depressive disorder & 0.186 & $1.50(0.82-2.74)$ & 0.665 & NS \\
\hline \multicolumn{5}{|l|}{ Concomitant conditions } \\
\hline Strain of muscle, fascial and tendon & 0.008 & $3.57(1.39-9.18)$ & 0.094 & NS \\
\hline Adhesions & 0.597 & $1.23(0.57-2.66)$ & NA & NA \\
\hline Low back pain & 0.002 & $2.48(1.40-4.41)$ & 0.003 & $2.44(1.36-4.40)$ \\
\hline Hernia status & 0.057 & $0.54(0.29-1.02)$ & 0.451 & NS \\
\hline \multicolumn{5}{|l|}{ Hernia type } \\
\hline Diaphragmatic hernia & 0.113 & $3.71(0.73-18.82)$ & 0.147 & NS \\
\hline Ventral hernia & 0.134 & $0.52(0.22-1.22)$ & 0.802 & NS \\
\hline Groin hernia & 0.286 & $2.21(0.52-9.48)$ & 0.162 & NS \\
\hline Incisional hernia & 0.538 & $0.52(0.06-4.26)$ & 0.594 & NS \\
\hline Umbilical hernia & 0.007 & $0.32(0.14-0.73)$ & 0.011 & $0.33(0.14-0.78)$ \\
\hline
\end{tabular}

Race categorized as categorical covariates with other variables were subjected to multivariate regression model using forward stepwise variable selection.

OR: odds ratio, Cl: confidence interval, N/A: not applicable, NS: not significant.

that the age at onset of LBP was significantly earlier than that of DD in postpartum women who had RAD. It is possible that LBP interacted with DD. Further study is warranted to discern which is the triggering factor.

PP and SMFT are risk factors of development of LBP in postpartum women with concomitant RAD. The authors demonstrated that women with PP had greater than 2 times the risk of development of LBP than those without PP. It was also worth noting that in the present study, women with SMFT had a 4.5 times greater risk of developing LBP than those without SMFT. SMFT is the most important manifestation of myofascial syndrome, being found to be the principal cause of pain [17-19]. In the present study, the authors hypothesize that, in the process of the development of chronic pain, the fascia plays a crucial role, since it is an uninterrupted, viscoelastic, continuous, collagen-containing tissue covering the entire body. Fascia interpenetrates and surrounds all organs, muscles, bones, and nerve fibers $[20,21]$. It has been reported that deep fascia might be closely related to non-specific LBP [22, 23]. The present study confirmed that SMFT was strongly related to LBP in postpartum women with RAD, which also stressed the importance of fascia in LBP.

LBP and Hispanic race are risk factors in the development of PP in postpartum women with concomitant RAD. The prevalence of $\mathrm{PP}$ among women varies from $6 \%$ to $27 \%$ $[24,25]$. In this study, the prevalence of PP was over onefifth among women with a history of delivery who had 
RAD. There was no significant difference in terms of age at onset of LBP/PP, regardless of delivery method. It was found that the prevalence of LBP in women with PP, with a rate of approximately $40 \%$, was significantly higher than those without PP. With univariate and multivariate regression analyses, the authors identified LBP as a risk factor related to PP. This suggested a close relationship between LBP and PP. While the consensus on whether race is a risk factor for chronic pain has not been reached $[9,26,27]$, it was intriguing that the authors found that Hispanic women had approximately a 4 -fold greater risk of developing PP, but not for developing LBP.

There are several clinical and research implications that follow this study. The prevalence of umbilical hernia RAD patients with PP was significantly lower than that of those without PP. Univariate and multivariate regression analysis also identified a negative association between pain and hernia. For clinicians and policy makers, the present study draws attention to women with RAD, as the authors revealed several common risk factors and potential complications. However, to the authors' knowledge, there is no prior literature that reports a link between umbilical hernia and PP, and prospective studies are necessary to further elaborate this matter. Additionally, the present study was not tailored towards finding the precise mechanism of the development of LBP and PP in women with RAD, though it may lead to its exploration in future research proposals. Once additional research has been completed, the authors' findings may be used in clinical settings.

Our study had several strengths and limitations. Ten years of data were included from multicenter information records, due to the retrospective nature of the study, many cases were excluded due to either no history of delivery or incomplete delivery operative notes, which may lead to sampling bias. The study focused on the association between LBP/PP and the first delivery, and the authors did not count the parity and plurality which might also interact with the pain, so these may have biased the results of this study.

It was reported that pain intensity was associated with RAD size and gestational trimester [28]. However, the current ICD coding mechanisms do not offer details of the data points. Fortunately, we included comprehensive analysis of concomitant conditions, which provided us with the opportunity to not only identify findings similar to multidisciplinary collaboration, but also study the association across more than a 15-year longitudinal span.

In conclusion, this study revealed the linkages and relationships between rectal abdominis diastasis, PP, and LBP in coordination with each other and additional factors such as delivery and race. We found that women with a history of CD were more likely to develop RAD, while the age of onset of RAD in women who underwent VD was significantly younger than those who underwent $\mathrm{CD}$. The authors also found that $\mathrm{LBP} / \mathrm{PP}$ were related to delivery, and the age at onset of LBP/PP showed no difference between the $\mathrm{CD}$ and non-CD groups in women with RAD. There was no significant difference in the age distribution at onset of LBP/PP among RAD women with or without CD exposure. In addition, DD, SMFT, and PP were risk factors contributing to the developing of LBP. Race and LBP also played roles in the development of PP. This paper sheds light on the characteristics of these conditions and sets the stage for additional research in this field of study.

\section{CONFLICT OF INTEREST}

No potential conflict of interest relevant to this article was reported.

\section{FUNDING}

No funding to declare.

\section{ORCID}

Sue Yuan, https://orcid.org/0000-0001-7120-4869

Honghong Wang, https://orcid.org/0000-0002-3484-8929

Jie Zhou, https://orcid.org/0000-0001-7701-234X

\section{REFERENCES}

1. Gitta S, Magyar Z, Tardi P, Füge I, Járomi M, Ács P, et al. [Prevalence, potential risk factors and sequelae of diastasis recti abdominis]. Orv Hetil 2017; 158: 454-60. Hungarian.

2. Fernandes da Mota PG, Pascoal AG, Carita AI, Bø K. Prevalence and risk factors of diastasis recti abdominis from late pregnancy to 6 months postpartum, and relationship with lumbo-pelvic pain. Man Ther 2015; 20: 200-5.

3. Reinpold W, Köckerling F, Bittner R, Conze J, Fortelny R, Koch A, et al. Classification of rectus diastasis-a proposal by the German Hernia Society (DHG) and the International Endohernia Society (IEHS). Front Surg 2019; 6: 1.

4. Sperstad JB, Tennfjord MK, Hilde G, Ellström-Engh M, Bø K. Diastasis recti abdominis during pregnancy and 12 months after childbirth: prevalence, risk factors and report of lumbopelvic pain. Br J Sports Med 2016; 50: 1092-6.

5. Li Y, Li S, Jiang J, Yuan S. Effects of yoga on patients with chronic nonspecific neck pain: a PRISMA systematic review and meta-analysis. Medicine (Baltimore) 2019; 98: e14649. 
6. Davenport MH, Marchand AA, Mottola MF, Poitras VJ, Gray CE, Jaramillo Garcia A, et al. Exercise for the prevention and treatment of low back, pelvic girdle and lumbopelvic pain during pregnancy: a systematic review and meta-analysis. Br J Sports Med 2019; 53: 90-8.

7. Doubkova L, Andel R, Palascakova-Springrova I, Kolar P, Kriz J, Kobesova A. Diastasis of rectus abdominis muscles in low back pain patients. J Back Musculoskelet Rehabil 2018; 31: 107-12.

8. Steffens D, Maher CG, Pereira LS, Stevens ML, Oliveira VC, Chapple M, et al. Prevention of low back pain: a systematic review and meta-analysis. JAMA Intern Med 2016; 176: 199208.

9. Vos T, Flaxman AD, Naghavi M, Lozano R, Michaud C, Ezzati $\mathrm{M}$, et al. Years lived with disability (YLDs) for 1160 sequelae of 289 diseases and injuries 1990-2010: a systematic analysis for the Global Burden of Disease Study 2010. Lancet 2012; 380: 2163-96.

10. Saxena AK, Chilkoti GT, Singh A, Yadav G. Pregnancyinduced low back pain in Indian women: prevalence, risk factors, and correlation with serum calcium levels. Anesth Essays Res 2019; 13: 395-402.

11. Gjestland K, Bø K, Owe KM, Eberhard-Gran M. Do pregnant women follow exercise guidelines? Prevalence data among 3482 women, and prediction of low-back pain, pelvic girdle pain and depression. Br J Sports Med 2013; 47: 515-20.

12. Akram J, Matzen SH. Rectus abdominis diastasis. J Plast Surg Hand Surg 2014; 48: 163-9.

13. Gluppe SL, Hilde G, Tennfjord MK, Engh ME, Bø K. Effect of a postpartum training program on the prevalence of diastasis recti abdominis in postpartum primiparous women: a randomized controlled trial. Phys Ther 2018; 98: 260-8.

14. Coldron Y, Stokes MJ, Newham DJ, Cook K. Postpartum characteristics of rectus abdominis on ultrasound imaging. Man Ther 2008; 13: 112-21.

15. Schmaling KB, Nounou ZA. Incident chronic spinal pain and depressive disorders: data from the National Comorbidity Survey. J Pain 2019; 20: 481-8.

16. Oon-Arom A, Likhitsathian S, Maneeton B, Sulaiman AH, Shih-Yen EC, Udomratn P, et al. Subjective depressive symp- toms associated with pain in patients with major depressive disorder: findings from the study on the aspect of Asian depression. Perspect Psychiatr Care 2020; 56: 188-93.

17. Takamoto K, Bito I, Urakawa S, Sakai S, Kigawa M, Ono T, et al. Effects of compression at myofascial trigger points in patients with acute low back pain: a randomized controlled trial. Eur J Pain 2015; 19: 1186-96.

18. Ramsook RR, Malanga GA. Myofascial low back pain. Curr Pain Headache Rep 2012; 16: 423-32.

19. Gerwin RD. Myofascial aspects of low back pain. Neurosurg Clin N Am 1991; 2: 761-84.

20. Adstrum S, Hedley G, Schleip R, Stecco C, Yucesoy CA. Defining the fascial system. J Bodyw Mov Ther 2017; 21: 173-7.

21. Dawidowicz J, Szotek S, Matysiak N, Mielańczyk Ł, Maksymowicz K. Electron microscopy of human fascia lata: focus on telocytes. J Cell Mol Med 2015; 19: 2500-6.

22. Schilder A, Magerl W, Hoheisel U, Klein T, Treede RD. Electrical high-frequency stimulation of the human thoracolumbar fascia evokes long-term potentiation-like pain amplification. Pain 2016; 157: 2309-17.

23. Benias PC, Wells RG, Sackey-Aboagye B, Klavan H, Reidy J, Buonocore D, et al. Structure and distribution of an unrecognized interstitium in human tissues. Sci Rep 2018; 8: 4947.

24. Silva GP, Nascimento AL, Michelazzo D, Alves Junior FF, Rocha MG, Silva JC, et al. High prevalence of chronic pelvic pain in women in Ribeirão Preto, Brazil and direct association with abdominal surgery. Clinics (Sao Paulo) 2011; 66: 1307-12.

25. Ahangari A. Prevalence of chronic pelvic pain among women: an updated review. Pain Physician 2014; 17: E141-7.

26. Green CR, Hart-Johnson T. The association between race and neighborhood socioeconomic status in younger Black and White adults with chronic pain. J Pain 2012; 13: 176-86.

27. Dobscha SK, Soleck GD, Dickinson KC, Burgess DJ, Lasarev $\mathrm{MR}$, Lee ES, et al. Associations between race and ethnicity and treatment for chronic pain in the VA. J Pain 2009; 10: 1078-87.

28. Santos MD, Silva RM, Vicente MP, Palmezoni VP, Carvalho EM, Resende AP. Does abdominal diastasis influence lumbar pain during gestation? Rev Dor São Paulo 2016; 17: 43-6. 